\title{
Gentianella acuta mitigates cardiovascular damage and inflammation in diet-induced hypercholesterolaemic rats
}

\author{
MINGDONG SI ${ }^{*}$, MENG WU $^{1 *}$, YINGYING HUO ${ }^{1,2},{\text { AIYING } \text { LI }^{3}, \text { SHENGJIANG GUAN }}^{4}$, \\ DONGLAI MA ${ }^{1,5}$ and ZHIHONG MA ${ }^{4}$
}

\begin{abstract}
${ }^{1}$ Department of Traditional Chinese Medicine, School of Pharmacy, Hebei University of Chinese Medicine, Shijiazhuang, Hebei 050200; ${ }^{2}$ Department of Traditional Chinese Medicine, College of Pharmaceutical Sciences, Yunnan University of Traditional Chinese Medicine, Kunming, Yunnan 650000; ${ }^{3}$ Hebei Higher Education Institute Applied Technology Research Center on TCM Formula Preparation, Shijiazhuang, Hebei 050091; ${ }^{4}$ Department of Immunology, School of Basic Medicine, Hebei University of Chinese Medicine; ${ }^{5}$ Traditional Chinese Medicine Processing Technology Innovation Center of Hebei Province, Shijiazhuang, Hebei 050200, P.R. China
\end{abstract}

Received December 10, 2020; Accepted June 29, 2021

DOI: $10.3892 / \mathrm{etm} .2021 .10694$

\begin{abstract}
Gentianella acuta (G. acuta) has been widely used as a traditional medicine by Chinese Mongolian populations for the treatment of heart diseases and has also been tested in modern pharmacological experiments. However, the effects of G. acuta on cardiovascular damage and inflammation under conditions of hypercholesterolaemia remain unclear. The present study investigated the effects and mechanisms of the water extract of G. acuta on cardiovascular damage and inflammation caused by a high-cholesterol diet. Male Sprague-Dawley rats were fed a high-cholesterol diet for 4 weeks to establish the hypercholesterolaemia rat model, and they were administered physiological saline or $1.2 \mathrm{~g} / \mathrm{kg}$ of $G$. acuta by gavage starting from the 15th day. After the last administration, the blood, heart and thoracic aorta samples were collected and examined. It was revealed that G. acuta treatment could ameliorate cardiomyocyte disorder and thoracic aortic vessel wall damage, reduce serum lipid levels and inflammatory factors and improve heart function. Compared with the Model group, the serum levels of triglycerides, total cholesterol, low-density lipoprotein and
\end{abstract}

Correspondence to: Dr Donglai Ma, Traditional Chinese Medicine Processing Technology Innovation Center of Hebei Province, 326 Xinshi South Road, Shijiazhuang, Hebei 050200, P.R. China

E-mail: mdl_hebei@aliyun.com

Dr Zhihong Ma, Department of Immunology, School of Basic Medicine, Hebei University of Chinese Medicine, 326 Xinshi South Road, Shijiazhuang, Hebei 050200, P.R. China

E-mail: mazh1969@163.com

*Contributed equally

Key words: Gentianella acuta, hypercholesterolaemia, cardiovascular disease, IKK/IкB/NF- $\kappa \mathrm{B}$ tumour necrosis factor- $\alpha$ were decreased, and the high-density lipoprotein and interleukin-10 levels were increased in the Model-G group. Moreover, in both the heart and thoracic aorta, G. acuta reduced the expression and phosphorylation of inhibitor of nuclear factor kappa-B kinase $\beta$ (IKK $\beta$ ), inhibitor of NF- $\kappa \mathrm{B}-\alpha(\mathrm{I} \kappa \mathrm{B} \alpha)$ and p-nuclear factor kappa-B $(\mathrm{NF}-\kappa \mathrm{B})$. Therefore, G. acuta may exert an inhibitory effect on the $\mathrm{IKK} / \mathrm{I} \kappa \mathrm{B} / \mathrm{NF}-\kappa \mathrm{B}$ signalling pathway to protect the heart and thoracic aorta in hypercholesterolaemic rats.

\section{Introduction}

Cardiovascular disease (CVD) is an important health concern and has been the focus of considerable research. In China, there are an estimated 330 million patients with CVD, and CVD accounts for $>40 \%$ of all disease-related resident deaths and has been identified as the leading cause of mortality (1). The mortality, incidence and prevalence rates of CVD continue to increase globally (1). Atherosclerosis (AS) is a major cause of CVD and the result of several factors, among which lipid metabolism disorders are the leading contributor. In modern society, lipid metabolism disorders are caused by hypercholesterolaemia and induce an inflammatory response that is involved in all processes of AS $(2,3)$. The nuclear transcription factor controlling their release is phosphorylated (p)-nuclear factor $\kappa \mathrm{B}(\mathrm{NF}-\kappa \mathrm{B})$, which has been revealed to induce an increase in the production of inflammatory and adhesion factors (4-6). Usually, $N F-\kappa B$ and the inhibitory protein inhibitor of $\mathrm{NF}-\kappa \mathrm{B}-\alpha(\mathrm{I} \kappa \mathrm{B} \alpha)$ exist as a complex and are inactive. However, when cells are stimulated or activated, the inhibitor of NF- $\kappa \mathrm{B}$ kinase $\beta$ (IKK $\beta$ ) phosphorylates and degrades $\mathrm{I} \kappa \mathrm{B} \alpha$, thus activating NF- $\kappa \mathrm{B}$. p-NF- $\kappa \mathrm{B}$ translocates into the nucleus, binds to related genes and regulates their transcription (7-10). In addition, numerous studies have reported that oxidative stress is an important cause of AS and is closely associated with NF- $\mathrm{BB}$ (11-13). Therefore, the occurrence of AS is closely linked to the IKK/I $\kappa \mathrm{B} / \mathrm{NF}-\kappa \mathrm{B}$ pathway. 
Gentianella acuta (Michx.) Hulten (G. acuta) belongs to the Gentianella genus of the Gentianaceae family, also known as the bitter gentian (14). The Elunchun people have been using $G$. acuta to treat arrhythmias and other heart diseases for thousands of years $(15,16)$. Previous studies on $G$. acuta mainly have focused on traditional efficacy, such as liver protection, and anti-arrhythmic, antioxidant and hypoglycaemic effects; however, further discoveries have been made in other fields (17); for example, the bioactive substances of G. acuta have been revealed to exert a beneficial effect on aberrant intestinal motility (18-20). Li et al (18) reported treatment with water extract of $G$. acuta could ameliorate cardiac structural disorders, excessive collagenous fiber accumulation in the heart and cardiac malfunction by regulating the $\mathrm{NF}-\kappa \mathrm{B}$ pathway in a model of myocardial fibrosis. Wang et al (21) indicated that xanthones from $G$. acuta exerted cardioprotective effects on myocardial ischemia/reperfusion (I/R) injury through its antioxidant and anti-apoptosis properties. Yang et al (22) indicated that the aqueous extract of $G$. acuta may improve isoproterenol-induced myocardial fibrosis through the inhibition of the tumour growth factor (TGF)- $\beta 1 /$ Smads signalling pathway. Numerous studies $(16,18,23-25)$ have reported that G. acuta exerted a protective effect against injury of the heart and the aorta of rats under various conditions, such as I/R. However, the effect and specific mechanism of action of G. acuta in cardiovascular damage and inflammation under hypercholesterolaemic conditions remain unclear. The aim of the present study was to explore the potential role of G. acuta in mitigating cardiovascular damage and inflammation in diet-induced hypercholesterolaemic rats.

\section{Materials and methods}

Collection and preparation of plant materials. G. acuta was purchased from The Darhan Muminggan Joint Banner mongolian medicine plantation, Hulunbeier district of Inner Mongolia and was identified and authenticated by Professor Yu-Ping Yan in the field of medicinal plants (College of Pharmacy, Hebei University of Chinese Medicine, Shijiazhuang, China). The plants were air-dried and then chopped. G. acuta $(64.51 \mathrm{~g})$ was soaked in $1,400 \mathrm{ml} 25^{\circ} \mathrm{C}$ distilled water for $30 \mathrm{~min}$. The mixture was boiled in two batches and combined twice with the filtrate. The mixture was used at a quantity of $537 \mathrm{ml}$ to obtain a suspension of $G$. acuta with a concentration of $0.12 \mathrm{~g} / \mathrm{ml}$.

Animals and experimental design. The Ethics Committee of Hebei University of Chinese Medicine (Shijiazhuang, China) approved and supervised the present study (approval no. DWLL2018016). A total of 32 specific-pathogen free male Sprague-Dawley (SD) rats, aged 6-7 weeks, weighing 160-180 g, were purchased from Beijing Vital River Laboratory Animal Technology Co., Ltd. (license no. SCXK 2016-0006) and all rats had free access to food and water. They were kept at room temperature with $60 \%$ humidity and 12-h light/dark cycle. After 1-week adaptive feeding, the rats were randomized into four groups (8) as follows: i) Control group (Control); ii) control administration group (Control-G), iii) model group (Model); and iv) model administration group
(Model-G). While animals in the Model and Model-G groups received a high-fat diet (high-fat feed ratio, $80.4 \%$ basic feed $+2 \%$ cholesterol $+10 \%$ lard $+0.5 \%$ sodium cholate $+0.1 \%$ propylthiouracil $+5 \%$ sugar $+2 \%$ yolk powder) to induce preliminary hypercholesterolaemia, Control and Control-G animals received normal feed (100\% basic feed: $248.48 \mathrm{~g} / \mathrm{kg}$ crude protein $+65.18 \mathrm{~g} / \mathrm{kg}$ crude fat). Normal and high-fat feed were provided and prepared by Hebei Medical University (Shijiazhuang, China). On the basis of the previous study, a $1.2 \mathrm{~g} / \mathrm{kg} \mathrm{G}$. acuta dosage solution was designed (26). After the third week of modelling, the rats of the Control-G and Model-G groups were administered water extract of G. acuta and the other groups were treated with the same $10 \mathrm{ml} / \mathrm{kg}$ of physiological saline for 2 weeks.

At the end of the experiment, all rats were only administered water for the final $12 \mathrm{~h}$. All rats were anesthetized with $50 \mathrm{mg} / \mathrm{kg}$ pentobarbital sodium (Merck KGaA) and euthanized using cervical dislocation. Following anaesthesia, blood was collected from the inferior vena cava for analysis of blood indicators. The serum was separated by centrifugation at $12,000 \mathrm{x}$ g for $15 \mathrm{~min}$ at $4^{\circ} \mathrm{C}$ and stored in a refrigerator at $-80^{\circ} \mathrm{C}$ for further analysis. The heart was weighed and fixed with the thoracic aorta in $10 \%(\mathrm{v} / \mathrm{v})$ formalin $24 \mathrm{~h}$ at room temperature for histopathological studies, and the rest of heart and thoracic aorta were stored at $-80^{\circ} \mathrm{C}$.

Blood biochemical index test. The serum levels of total cholesterol (TC; cat. no. OSR6216; Beckman Coulter, Inc.), triglycerides (TG; cat. no. OSR61118; Beckman Coulter, Inc.), low-density lipoprotein (LDL; cat. no. A113-1-1; Nanjing Jiancheng Bioengineering Institute), high-density lipoprotein (HDL; cat. no. A112-1-1; Nanjing Jiancheng Bioengineering Institute), lactate dehydrogenase (LDH; cat. no. A020-1-2; Nanjing Jiancheng Bioengineering Institute), creatine kinase (CK; cat. no. A032-1-1; Nanjing Jiancheng Bioengineering Institute), tumour necrosis factor- $\alpha$ (TNF- $\alpha$; cat. no. SXR063; Shanghai Senxiong Biotech Industry, Co., Ltd.) and interleukin-10 (IL-10; cat. no. SXR035; Shanghai Senxiong Biotech Industry, Co., Ltd.) were assessed strictly according to the manufacturer's instructions.

Histopathological examination of the heart and thoracic aorta. The heart and thoracic aortas isolated from each group were fixed in $10 \%$ (v/v) formalin in $50 \mathrm{~mm}$ potassium phosphate buffer $\left(\mathrm{pH} \mathrm{7.0)}\right.$ for $24 \mathrm{~h}$ at $4^{\circ} \mathrm{C}$. The tissues were subsequently embedded in paraffin, cut into $4-\mu \mathrm{m}$ sections, and stained $5 \mathrm{~min}$ at room temperature with hematoxylin and then 1 min with eosin at room temperature. The sections were observed and images were captured using a light microscope with a Leica DFC 320 digital camera (magnification, x400; Leica Microsystems, Inc.).

Immunohistochemical analysis of IKK $\beta, p-I K K \beta, I \kappa B \alpha$ and $p-I \kappa B \alpha$ in the heart and thoracic aorta. Each section was dewaxed with a dimethylbenzene gradient and dehydrated using an alcohol gradient. The sections were then incubated with $3 \% \mathrm{H}_{2} \mathrm{O}_{2}$ for $15 \mathrm{~min}$ in the dark, blocked with $100 \%$ goat serum for $20 \mathrm{~min}$ at room temperature (cat. no. ZLI-9056; ZSGB-BIO; OriGene Technologies, Inc.), and then rinsed three times with PBS. The primary antibodies [IKK $\beta$ (1:100; 

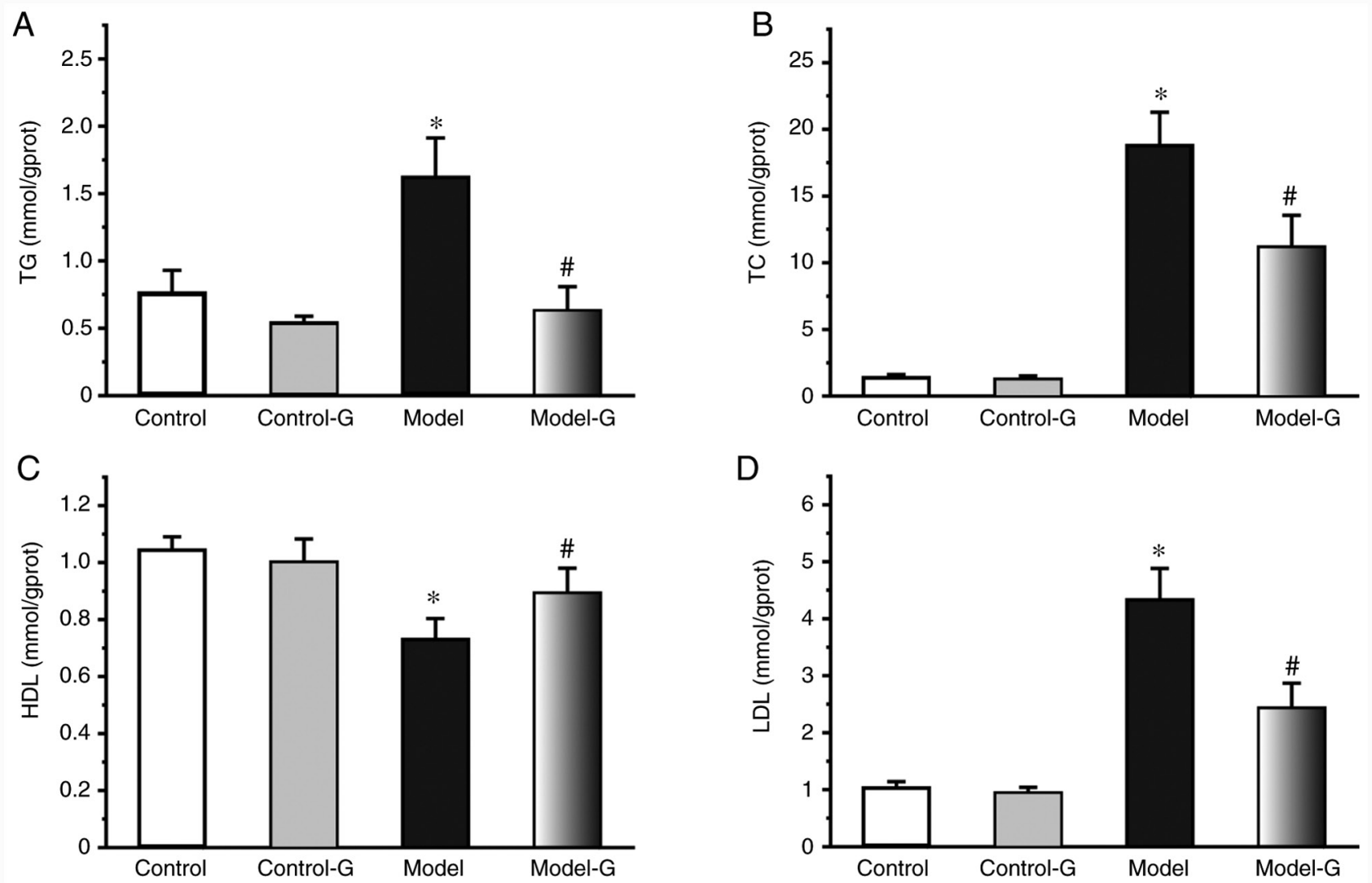

Figure 1. Effects of G. acuta on serum lipid levels. Serum (A) TG, (B) TC, (C) HDL and (D) LDL levels following treatment with G. acuta. Data are presented as the mean $\pm \mathrm{SD}$. ${ }^{*} \mathrm{P}<0.05$ vs. the Control group; ${ }^{*} \mathrm{P}<0.05$ vs. the Model group ( $\mathrm{n}=8$ per group). G. acuta, Gentianella acuta; TG, triglycerides; TC, total cholesterol; HDL, high-density lipoprotein; LDL, low-density lipoprotein.
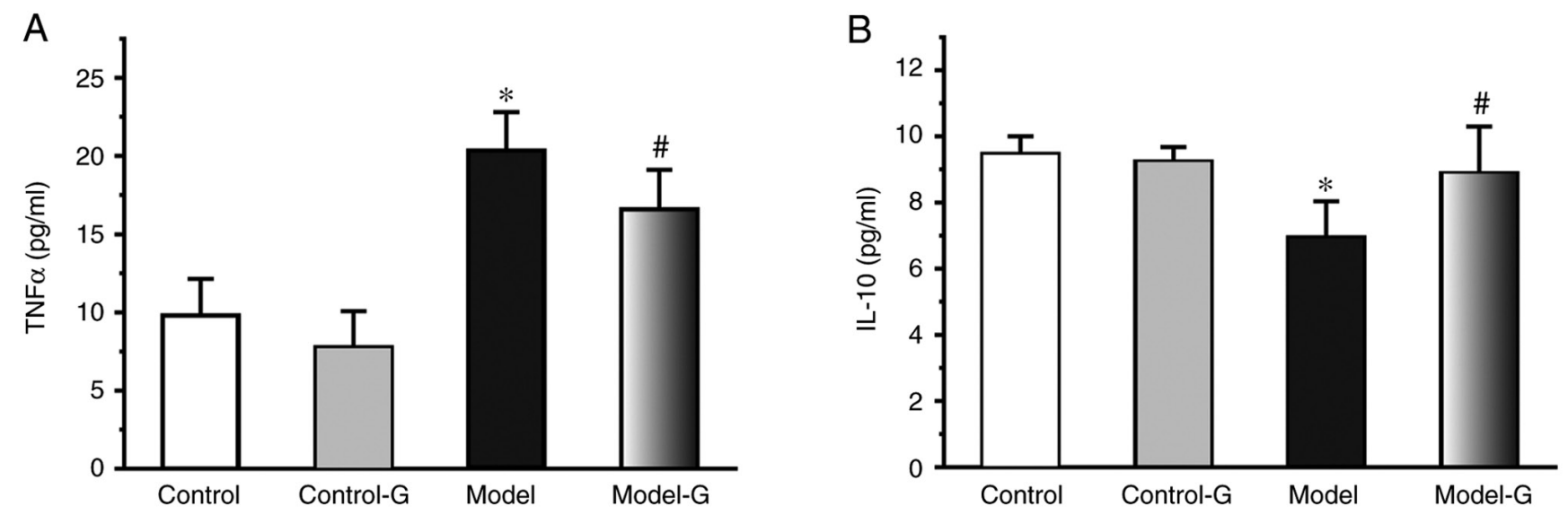

Figure 2. Effects of G. acuta on TNF- $\alpha$ and IL-10 levels in the serum. Serum (A) TNF- $\alpha$ and (B) IL-10 levels following treatment with G. acuta. Data are presented as the mean $\pm \mathrm{SD}$. ${ }^{*} \mathrm{P}<0.05$ vs. the Control group; ${ }^{*} \mathrm{P}<0.05$ vs. the Model group ( $\mathrm{n}=8$ per group). G. acuta, Gentianella acuta; $\mathrm{TNF}-\alpha$, tumour necrosis factor- $\alpha$; IL-10, interleukin-10.

cat. no. A2087; ABclonal Biotech Co., Ltd.), p-IKK $\beta$ (1:400; cat. no. bs-5398R), IкB $\alpha(1: 800 ;$ cat. no. bsm-33441M) and p-IкB $\alpha(1: 200$; cat. no. bs-5515R; all from BIOSS)] were incubated with the sections at $4^{\circ} \mathrm{C}$ overnight. Next, rabbit two-step HRP-secondary antibody polymers (cat. no. PV-6001; ZSGB-BIO; OriGene Technologies, Inc.) were added for $60 \mathrm{~min}$ at room temperature and then the avidin-biotinperoxidase complex (cat. no. PK-6200; Vector Laboratories, Inc.; Maravai LifeSciences) was added for $120 \mathrm{~min}$ at room temperature. The sections were stained with diaminobenzidine (DAB) reagent $10 \mathrm{~min}$ at room temperature, dehydrated with alcohol gradient and DAB and finally mounted using neutral balsam. The sections were viewed under a light microscope (magnification, x400) and analyzed using ImageJ software (v. d1.47; National Institutes of Health).

Western blot analysis for $p-I K K \beta, p-I \kappa B \alpha$ and $p-N F-\kappa B$ in the heart and $p-N F-\kappa B$ in the thoracic aorta. The protein extract 
A

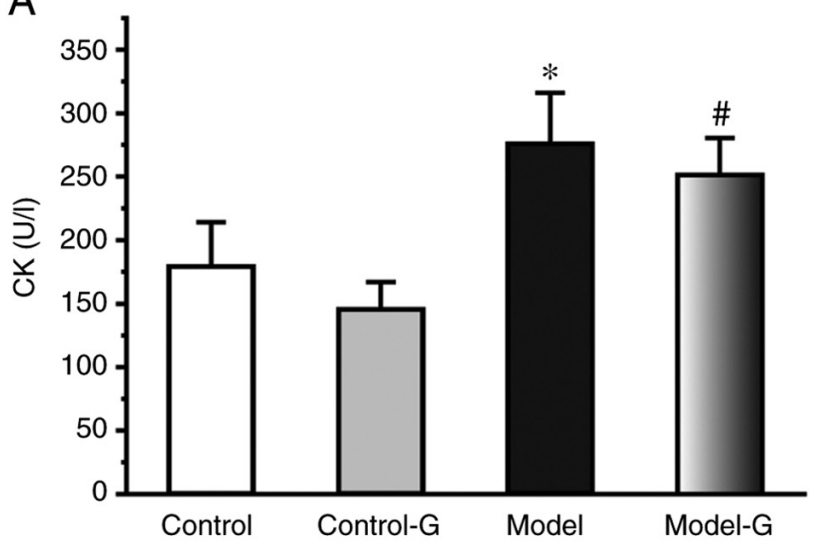

B

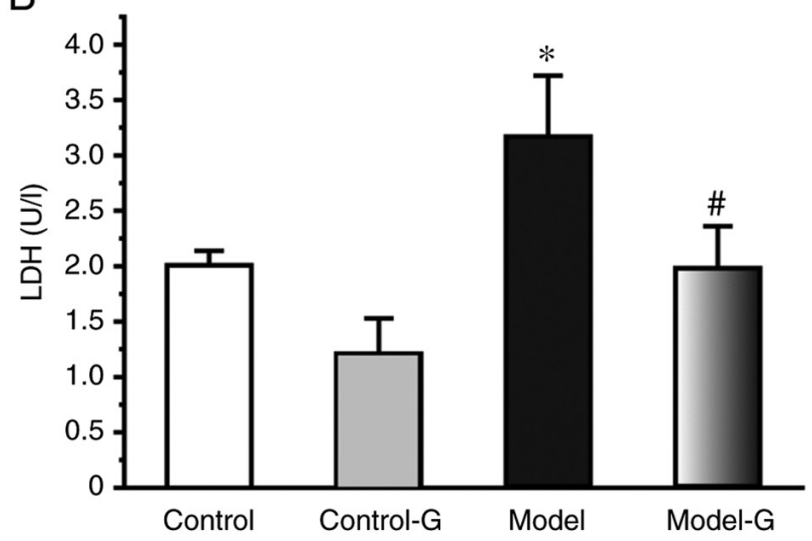

Figure 3. Effects of G. acuta on CK and LDH levels in the serum. Serum (A) CK and (B) LDH levels following treatment with G. acuta. Data are presented as the mean $\pm \mathrm{SD}$. ${ }^{*} \mathrm{P}<0.05$ vs. the Control; ${ }^{\text {}} \mathrm{P}<0.05$ vs. the Model group ( $\mathrm{n}=8$ per group). G. acuta, Gentianella acuta; CK, creatine kinase; LDH, lactate dehydrogenase.

A

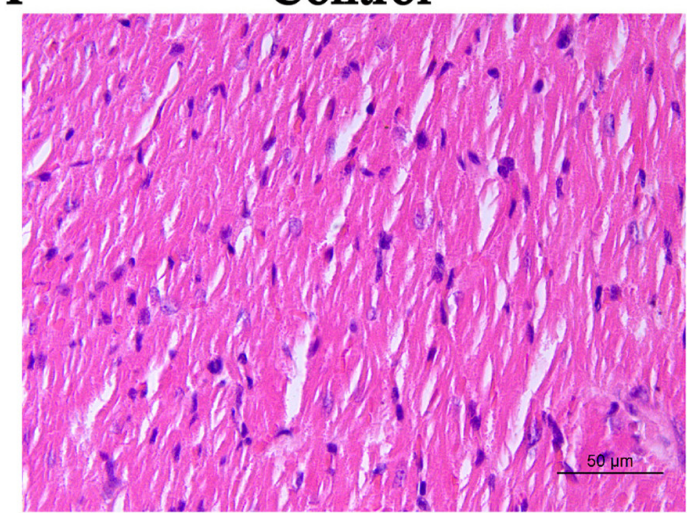

$\mathrm{C}$

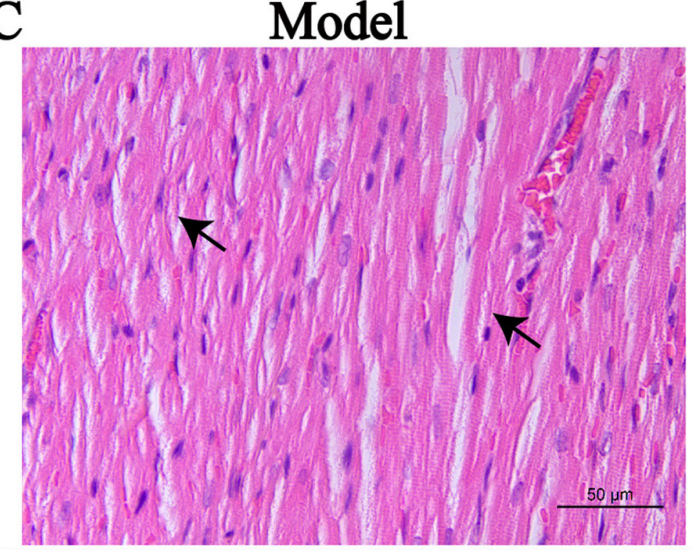

B

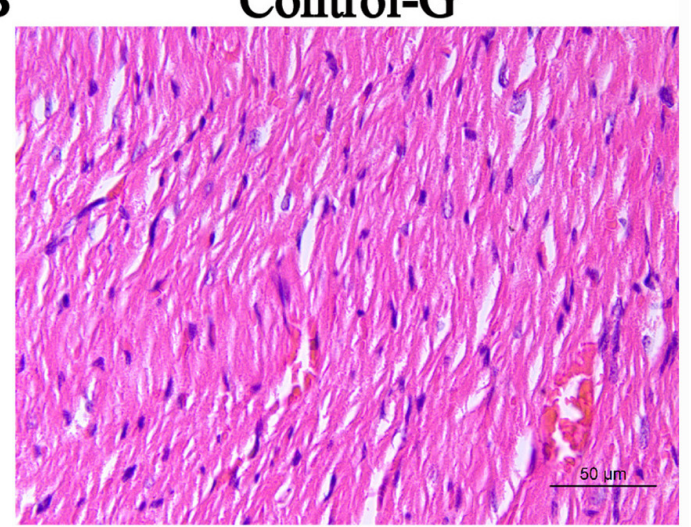

D

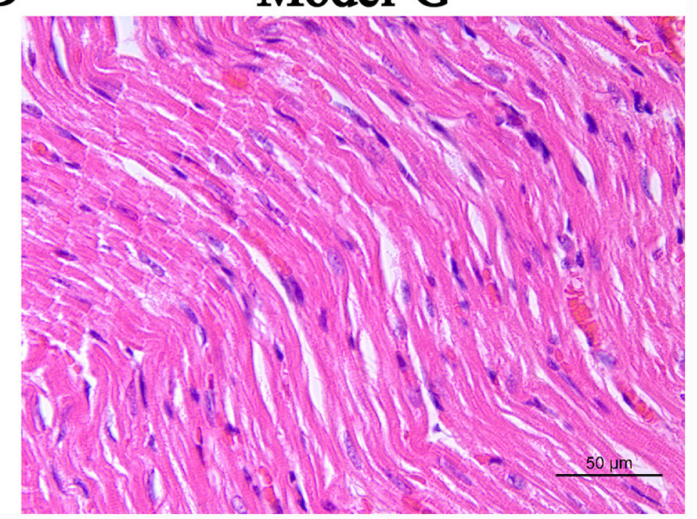

Figure 4. Effects of G. acuta on the histopathological changes in the heart. Heart tissues obtained from the (A) Control, (B) Control-G, (C) Model and (D) Model-G groups. The arrows indicated histopathological changes in the Model group. Scale bar, $50 \mu \mathrm{m}$. G. acuta, Gentianella acuta.

from the frozen tissues of the heart and thoracic aorta were determined using a BCA Protein Assay Kit (cat. no. P0010; Beyotime Institute of Biotechnology) to ensure $20 \mu \mathrm{g}$ protein per lane and were separated by $10 \%$ SDS-PAGE and then transferred onto polyvinylidene difluoride membranes. Membranes were blocked $4^{\circ} \mathrm{C}$ for $5 \mathrm{~h}$ with $5 \%$ non-fat dry milk in Tris-buffered saline with $0.05 \%$ Tween-20 and left overnight. The blots were incubated with primary antibodies for GAPDH (1:1,000; cat. no. bs-0755R; BIOSS), IKK $\beta$ (1:100; cat. no. AF6013; Affinity Biosciences), p-IKK $\beta$ (1:400; cat. no. bs-5398R), IкB $\alpha$ (1:800; cat. no. bsm-33441M),

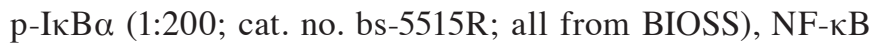
(1:1,000; product no. 8242; Cell Signaling Technology, Inc.), p-NF-кB (1:250; cat. no. ab247871; Abcam) overnight at $4^{\circ} \mathrm{C}$ and then incubated with a secondary antibody $(1: 10,000$; cat. no. ZB2301; ZSGB-BIO; OriGene Technologies, Inc.) 
A
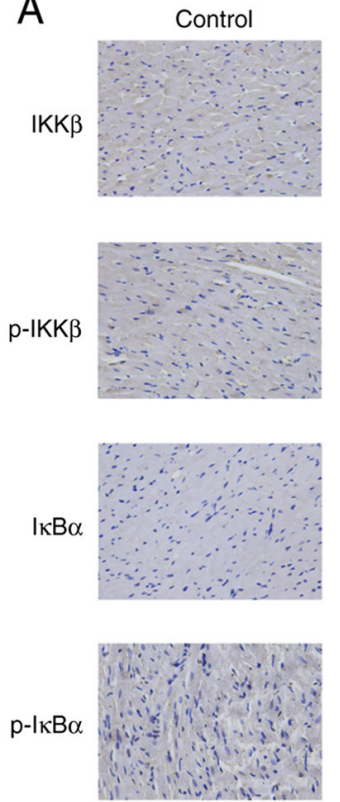

D
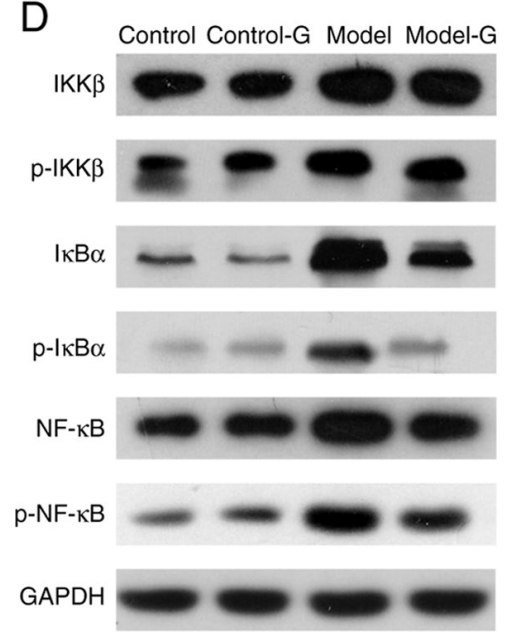

Model
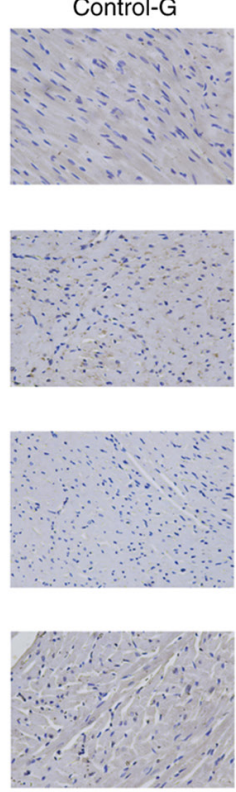

Model-G
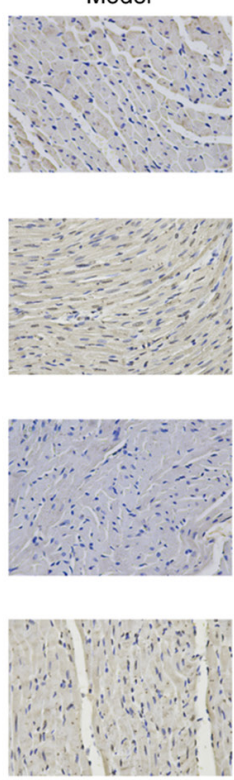

E

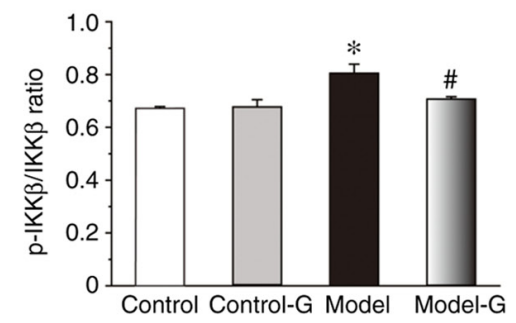

$\mathrm{G}$

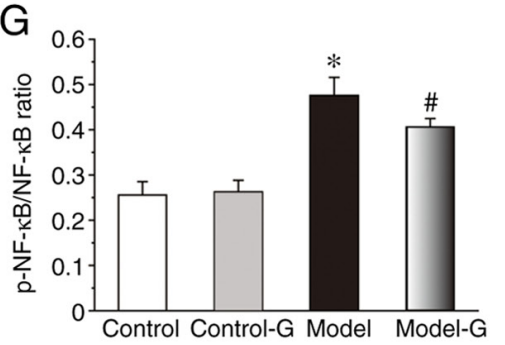

B

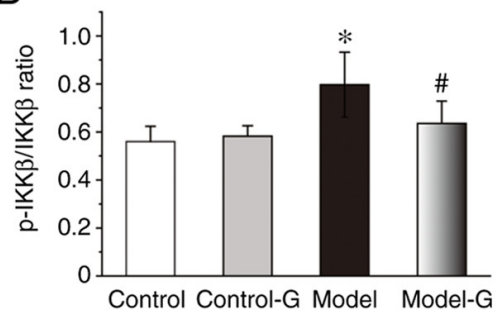

C

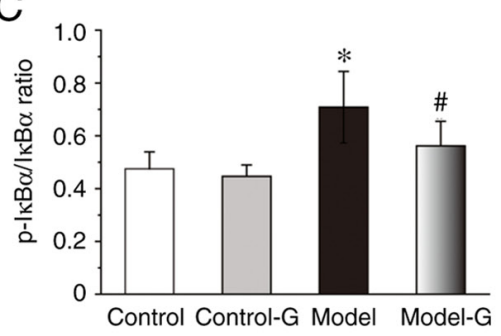

$\mathrm{F}$

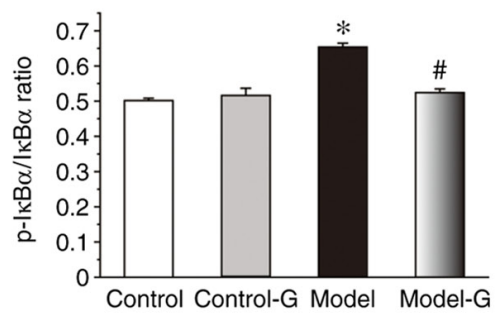

Figure 5. Effects of $G$. acuta on p-IKK $\beta, \mathrm{IKK} \beta, \mathrm{p}-\mathrm{I} \kappa \mathrm{B} \alpha, \mathrm{I} \kappa \mathrm{B} \alpha$ and $\mathrm{p}-\mathrm{NF}-\kappa \mathrm{B}$ expression levels in the heart. (A) Immunohistochemical staining for $\mathrm{p}-\mathrm{IKK} \beta, \mathrm{IKK} \beta$, $\mathrm{p}-\mathrm{I} \kappa \mathrm{B} \alpha$ and $\mathrm{I} \kappa \mathrm{B} \alpha$ in the heart (magnification, $\mathrm{x} 400$ ). Heart tissues were obtained from the Control, Control-G, Model and Model-G groups. (B) Expression of $\mathrm{p}$-IKK $\beta / \mathrm{IKK} \beta$ in the heart. (C) Expression of $\mathrm{p}-\mathrm{I} \kappa \mathrm{B} \alpha / \mathrm{I} \kappa \mathrm{B} \alpha$ in the heart. (D) Typical western blot bands. (E) Expression of $\mathrm{p}$-IKK $\beta / \mathrm{IKK} \beta$ in the heart was quantified by densitometry. (F) Expression of $\mathrm{p}-\mathrm{I} \kappa \mathrm{B} \alpha / \mathrm{I} \kappa \mathrm{B} \alpha$ in the heart was quantified by densitometry. (G) Expression of p-NF- $\kappa \mathrm{B} / \mathrm{NF}-\kappa \mathrm{B}$ in the heart was quantified by densitometry. Scale bar, $200 \mu \mathrm{m}$. Data are presented as the mean $\pm \mathrm{SD}$. ${ }^{*} \mathrm{P}<0.05$ vs. the Control group and ${ }^{\#} \mathrm{P}<0.05$ vs. the Model group (Immunohistochemistry: $\mathrm{n}=8$ per group; western blot: $\mathrm{n}=3$ per group). G. acuta, Gentianella acuta; p-, phosphorylated; IKK $\beta$, inhibitor of NF- $\kappa \mathrm{B}$ kinase $\beta$; $\mathrm{I} \kappa \mathrm{B} \alpha$, inhibitor of $\mathrm{NF}-\kappa \mathrm{B} \alpha$; NF- $\kappa \mathrm{B}$, nuclear factor $\kappa \mathrm{B}$.

conjugated to horseradish peroxidase (1:6,500; Biosharp Life Sciences) for $2 \mathrm{~h}$ at room temperature. After the treatment of Super ECL Detection Reagent (cat. no. 36208ES60; Shanghai Yeasen Biotechnology Co., Ltd.), the protein bands were quantified by transmittance densitometry using ImageJ software (v. d1.47; National Institutes of Health). The relative protein band intensity was expressed as the ratio of each protein to the reference GAPDH.

Statistical analysis. All statistical analyses were completed using SPSS 22.0 software (IBM Corp). The data are presented as the mean \pm SD. Differences among the four groups were assessed using one-way analysis of variance followed by
Tukey's post hoc test. $\mathrm{P}<0.05$ was considered to indicate a statistically significant difference.

\section{Results}

Effects of G. acuta on serum lipids. Compared with the Control group, the TG, TC and LDL levels of the Model and Model-G groups were significantly increased, while the HDL level was significantly decreased $(\mathrm{P}<0.05)$. In addition, the levels of TG, TC and LDL were significantly decreased, and those of HDL were significantly increased in the Model-G group compared with those in the Model group (Fig. 1; $\mathrm{P}<0.05)$. 
A

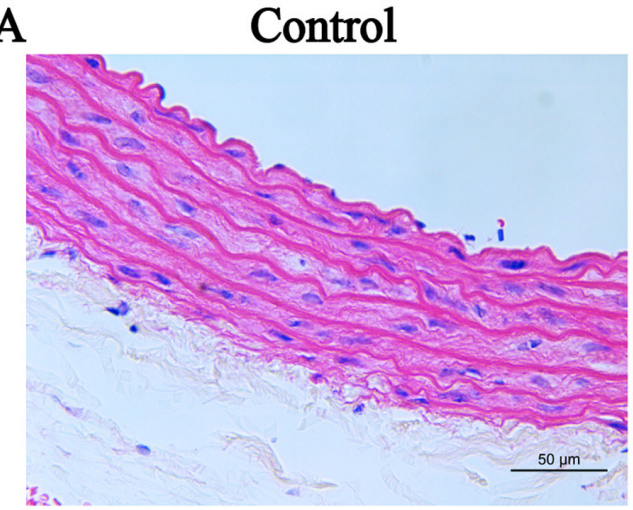

$\mathrm{C}$

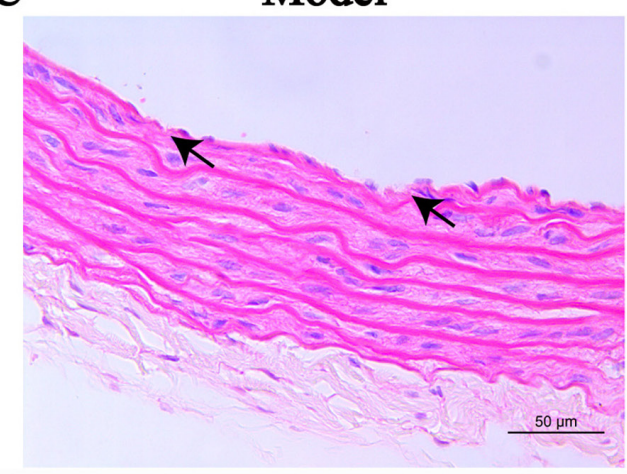

B

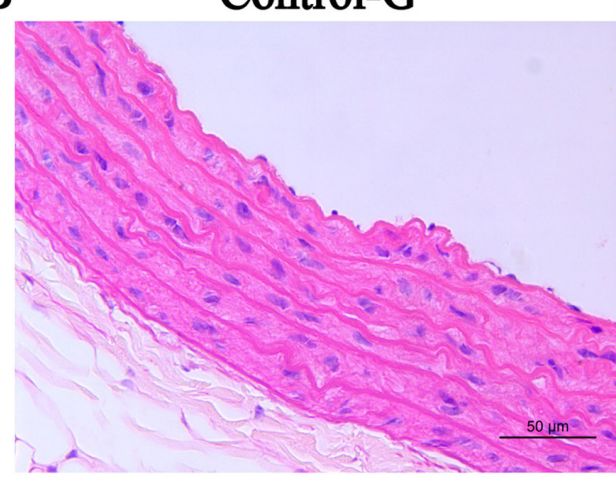

D

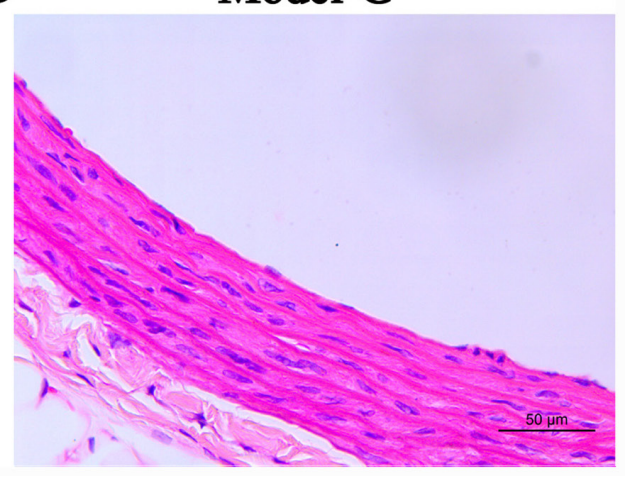

Figure 6. Effect of G. acuta on histopathological changes of the thoracic aorta. Thoracic aorta samples obtained from the (A) Control, (B) Control-G, (C) Model and (D) Model-G groups. The arrows indicate histopathological changes in the Model group. Scale bar, $50 \mu \mathrm{m}$. G. acuta, Gentianella acuta.

Effects of G. acuta on IL-10 and TNF- $\alpha$ in the serum. Compared with the Control group, the TNF- $\alpha$ levels in the Model group were increased $>2$-fold $(\mathrm{P}<0.05)$. Compared with the Model group, TNF- $\alpha$ was significantly decreased in the Model-G group $(\mathrm{P}<0.05)$. The IL-10 levels in the Model group were significantly decreased compared with those in the Control and Model-G groups (Fig. 2; P>0.05).

Effects of G. acuta on CK and LDH in the serum. The CK and LDH levels of the Model group were significantly higher compared with those of the Control and Model-G groups $(\mathrm{P}<0.05)$. Compared with the Model group, the level of CK and LDH were significantly decreased in the Model-G group ( $\mathrm{P}<0.05$; Fig. 3).

Effects of G. acuta on morphological and histological changes in the heart. The cardiomyocytes in the Control group were arranged in an orderly manner with uniform nuclei, uniform H\&E staining of the cytoplasm and obvious striations. The arrangement of cardiomyocytes in the Model group was disordered, with burrs, slightly blurry striations, and certain sections were revealed to have lipid droplets. The arrangement of cardiomyocytes in the Model-G group was improved and appeared orderly (Fig. 4).

Effect of $G$. acuta on IKK/I $B / N F-\kappa B$ in the heart. The IKK $\beta$, $\mathrm{p}-\mathrm{IKK} \beta$ and $\mathrm{p}-\mathrm{I} \kappa \mathrm{B} \alpha$ protein expression levels of the Model group were markedly higher compared with those in the other three groups. While changes in the expression of $\mathrm{I} \kappa \mathrm{B} \alpha$ were not significant among the four groups, the levels of $\mathrm{p}-\mathrm{IKK} \beta / \mathrm{IKK} \beta$ and $\mathrm{p}-\mathrm{I} \kappa \mathrm{B} \alpha / \mathrm{I} \kappa \mathrm{B} \alpha$ in the Model group were significantly higher than the other groups (Fig. 5A-C). Compared with the Control and Model-G groups, the protein levels of $\mathrm{p}-\mathrm{IKK} \beta / \mathrm{IKK} \beta$, $\mathrm{p}-\mathrm{I} \kappa \mathrm{B} \alpha / \mathrm{I} \kappa \mathrm{B} \alpha$ and $\mathrm{p}-\mathrm{NF}-\kappa \mathrm{B} / \mathrm{NF}-\kappa \mathrm{B}$ in the Model group were significantly increased (Fig. 5D-G).

Effects of G. acuta on morphological and histological changes in the thoracic aorta. The arterial intima in the Control group was relatively smooth, with clear boundaries between the intima, media and adventitia, and endothelial cell layer continuity. The intima of the arteries of the Model group was uneven, and some endothelial cells had lost their continuity. Intimal concavity was improved in the Model-G group. The intima of the Control-G group was damaged (Fig. 6).

Effect of $G$. acuta on IKK/I $\kappa B / N F-\kappa B$ in the thoracic aorta. The IKK $\beta, p-I K K \beta$ and $\mathrm{p}-\mathrm{I} \kappa \mathrm{B} \alpha$ protein expression levels of the Model group were significantly higher compared with those in the other three groups. While the changes in the expression of I $\mathrm{B} \alpha$ were not significant among the four groups, the levels of $\mathrm{p}-\mathrm{IKK} \beta / \mathrm{IKK} \beta$ and $\mathrm{p}-\mathrm{I} \kappa \mathrm{B} \alpha / \mathrm{I} \kappa \mathrm{B} \alpha$ in the Model group were higher than the other three groups (Fig. 7A-C). Compared with the Model group, the levels of $\mathrm{p}-\mathrm{NF}-\kappa \mathrm{B} / \mathrm{NF}-\kappa \mathrm{B}$ in the Control and Model-G groups were significantly decreased (Fig. 7D and E).

\section{Discussion}

Several studies have reported that hypercholesterolaemia is not only a risk factor for AS development, but also an important 
A
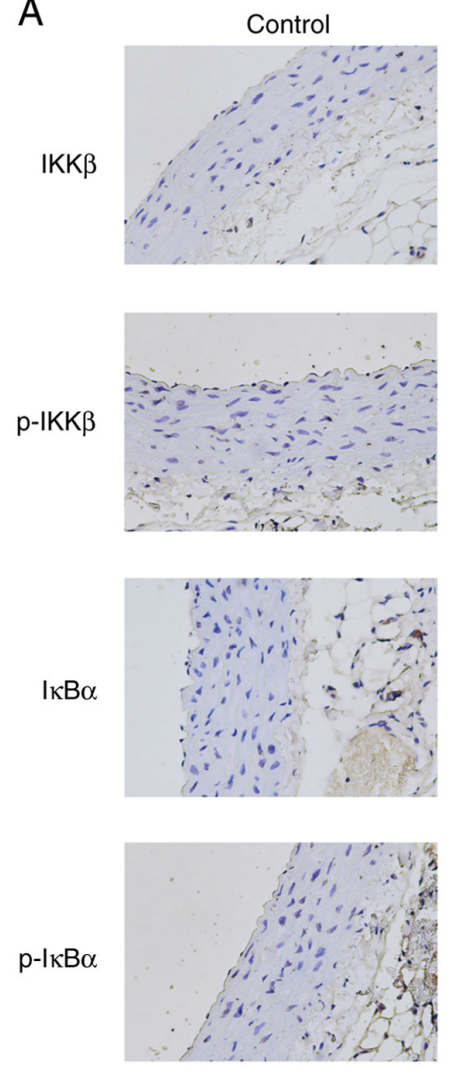

B

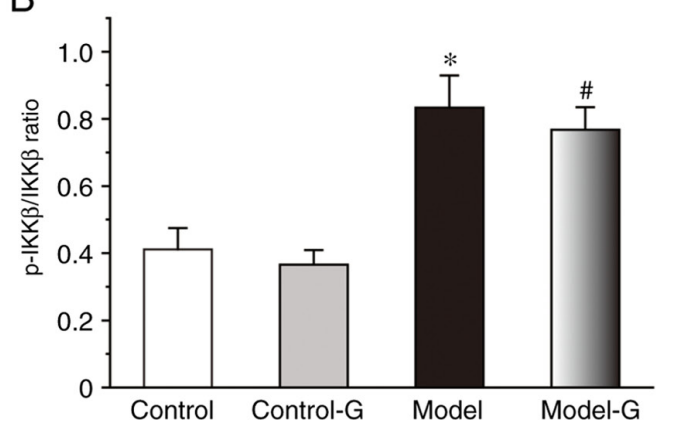

D
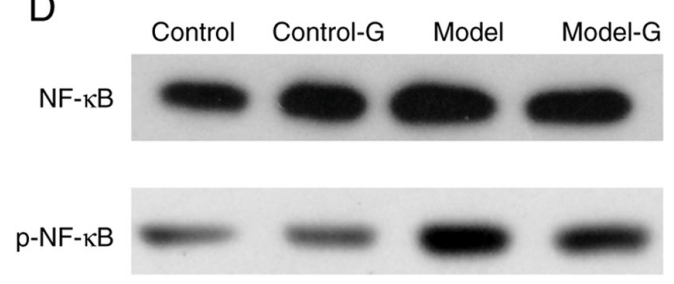

GAPDH

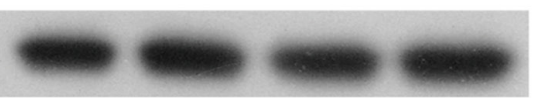

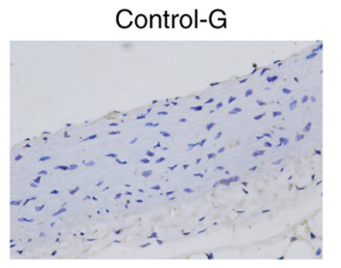
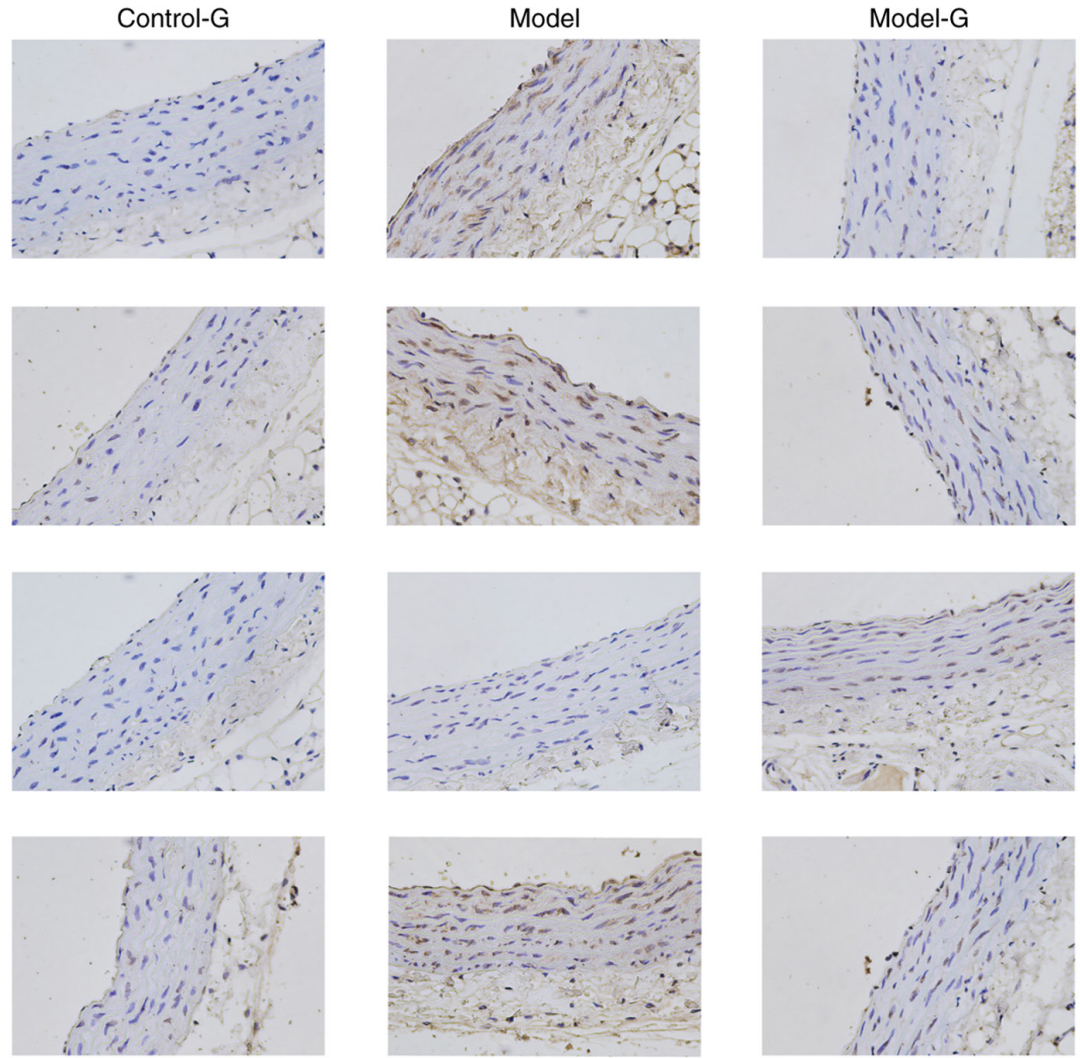

C

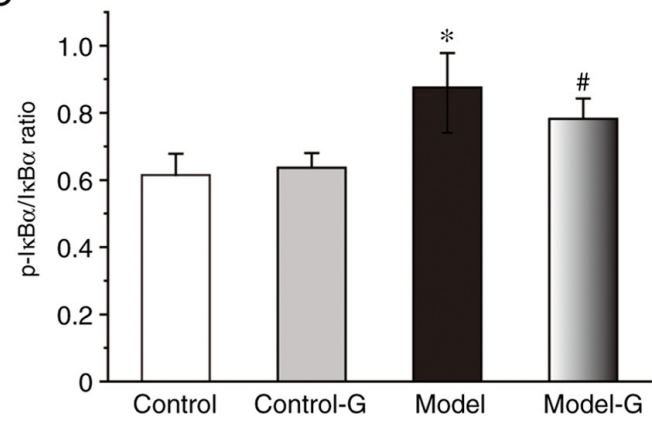

E

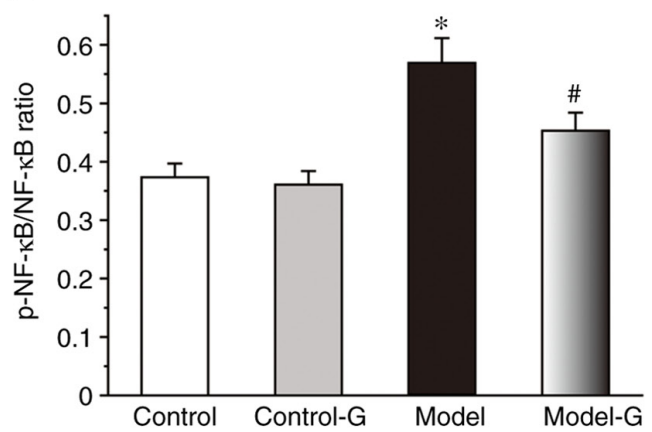

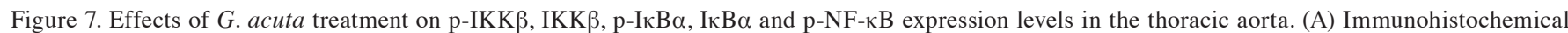

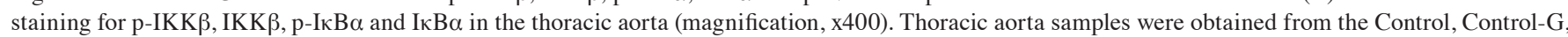
Model and Model-G groups. (B) Expression of p-IKK $\beta / \mathrm{IKK} \beta$ in the thoracic aorta. (C) Expression of $\mathrm{p}-\mathrm{I} \kappa \mathrm{B} \alpha / \mathrm{I} \kappa \mathrm{B} \alpha$ in the thoracic aorta. (D) Typical western blot bands. (E) Expression of p-NF- $\kappa \mathrm{B} / \mathrm{NF}-\kappa \mathrm{B}$ in the thoracic aorta was quantified by densitometry. Scale bar, $200 \mu \mathrm{m}$. Data are presented as the mean \pm SD. ${ }^{*} \mathrm{P}<0.05$ vs. the Control group; ${ }^{*} \mathrm{P}<0.05$ vs. the Model group (Immunohistochemical: $\mathrm{n}=8$ per group; western blot: $\mathrm{n}=3$ per group). G. acuta, Gentianella acuta;

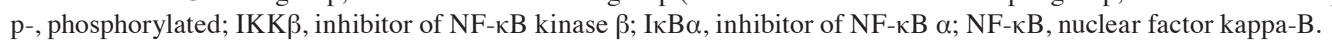

cause of the exacerbation of AS $(27,28)$. It has been revealed that G. acuta exerts a protective effect against myocardial ischemia (19). On this basis, its anti-AS effects and mechanism were studied herein. In the present study, a rat model 
of hypercholesterolaemia was established using a high-fat diet (29) to explore the effect and mechanisms of G. acuta in mitigating cardiovascular damage and inflammation.

Hypercholesterolaemia model rats exhibited increases in serum lipids and inflammatory factors, aortic muscular layer thickening and widespread myocardial structural disruption. These histopathological changes in the body were important formative indices of hypercholesterolaemia, with some beneficial changes appearing in the Model-G group, such as improved aortic wall structure and neatly arranged myocardial cells. Lipid deposition has been identified as an important cause of AS, which can lead to the increase of free radicals, thereby damaging endothelial cell function (30-32). Thus, the release of protective factors is reduced, leading to a reduction in the tightness of endothelial cells and increased permeability, which in turn results in increased lipid deposition, forming a vicious circle (33). As a consequence of a continuous high-fat diet, LDL is elevated and deposited in the endothelial cells of the arteries in which it is oxidized to ox-LDL, which can cause necrosis and disintegration of macrophages, release of lipids from atheromatous necrosis and plaque formation (34). When comparing the Model-G and the Model groups, it was revealed that $G$. acuta could effectively reduce the serum lipid level with further increasing the level of HDL.

A change in TNF- $\alpha$ and IL-10 levels in the serum of hypercholesterolaemic rats was also observed. TNF- $\alpha$ and IL-10 are important inflammatory factors leading to AS. TNF- $\alpha$ has been reported to promote the production of various inflammatory cytokines through $\mathrm{T}$ cells and has been identified as an important indicator of inflammation (35). Conversely, IL-10 has been reported to inhibit mononuclear macrophages from performing specific immune functions, such as the release of inflammatory mediators (36). Compared with the Control group, the levels of TNF- $\alpha$ were significantly increased, and those of IL-10 were decreased in the Model group. Following treatment with G. acuta, TNF- $\alpha$ and IL-10 levels were significantly altered in the Model group. These results demonstrated that the inflammatory response induced by the high-fat diet was inhibited by G. acuta.

CK and LDH have been revealed to be important indices reflecting functional heart status (37). Compared with the control group, the levels of CK and LDH in the blood vessels of the Model group were significantly decreased, indicating the protective effect of G. acuta in the heart. It was also revealed by $H \& E$ staining that the arrangement of cardiomyocytes in the Model-G group was improved and appeared orderly. These results further demonstrated that G. acuta effectively alleviated cardiovascular damage and inflammation in diet-induced hypercholesterolaemic rats.

$\mathrm{NF}-\kappa \mathrm{B}$ has been identified as an important nuclear factor that controls inflammatory cytokines and is normally bound to I $\mathrm{B}$ in the cytoplasm. After NF- $\kappa \mathrm{B}$ has been activated and translocated to the nucleus, several downstream inflammation-related factors, such as TNF- $\alpha$ and IL- 6 , promote its synthesis and release. Such factors are important causes of the occurrence and deterioration of AS (38-40). As a pattern recognition receptor, activated IKK is a major upstream target for $\mathrm{NF}-\kappa \mathrm{B}$ regulation. Multiple members of the IKK family, such as IKK $\alpha$ and IKK $\beta$, have important regulatory effects on the activity of $N F-\kappa B$. Both of these have been revealed to phosphorylate the $\mathrm{I} \kappa \mathrm{B}$ protein at different serine residues, while the main function has been assumed by $\operatorname{IKK} \beta$ (41). Thus, IKK $\beta$ is an important indicator of NF- $\mathrm{NB}$ activation. When $G$. acuta was administered, the expression of $\mathrm{p}-\mathrm{IKK} \beta / \mathrm{IKK} \beta$ and $\mathrm{p}-\mathrm{I} \kappa \mathrm{B} \alpha / \mathrm{I} \kappa \mathrm{B} \alpha$ both in the heart and thoracic aorta in the Model-G group were significantly decreased. Compared with the Model group, the phosphorylation ratio of IKK $\beta, \mathrm{I} \kappa \mathrm{B} \alpha, \mathrm{NF}-\kappa \mathrm{B}$ in the heart and $\mathrm{NF}-\kappa \mathrm{B}$ in thoracic aorta was decreased in the Model-G group. In addition, $G$. acuta significantly decreased the expression levels of IKK $\beta, p-I K K \beta$ and $p-I \kappa B \alpha$ in endothelial cells of the thoracic aorta, indicating its protective role. These results demonstrated that the anti-inflammatory effect of G. acuta may be mediated by inhibiting the IKK $\beta / \mathrm{I} \kappa \mathrm{B} \alpha / \mathrm{NF}-\kappa \mathrm{B}$ pathway in the heart as well as the thoracic aorta.

In conclusion, G. acuta mitigated cardiovascular damage and inflammation in diet-induced hypercholesterolaemic rats, possibly through the inhibition of the IKK- $\beta / \mathrm{I} \kappa \mathrm{B} / \mathrm{NF}-\kappa \mathrm{B}$ pathway. Thus, G. acuta may prove useful in the treatment of hypercholesterolaemia.

A limitation of the present study was that it lacked direct assessment of physiological parameters and immunohistochemical analysis could reveal the expression levels but was weaker in protein comparison than western blotting in thoracic aorta. In addition, G. acuta water extract was selected, but water extract is comprised of numerous components and these were not fractionated and explored individually.

\section{Acknowledgements}

The authors would like to thank Professor Gang Cao and Professor Huazhou Xu (School of Basic Medicine, Hebei University of Chinese Medicine, Shijiazhuang, China) for technical assistance.

\section{Funding}

The present was supported by the National Natural Science Foundation of China (grant no. 81573698), the innovative research program for postgraduate of Hebei University of Chinese Medicine (grant no. XCXZZSS2021003) and the 333 Talent Project of Hebei (grant no. 2020-7).

\section{Availability of data and materials}

The datasets used and/or analyzed during the current study are available from the corresponding author on reasonable request.

\section{Authors' contributions}

DM and ZM conceived the project and designed the experiments. AL and SG carried out the experiments. MS, MW and $\mathrm{YH}$ established the rat model of hypercholesterolaemia and carried out the experiments. YH conducted the statistical analysis. MS and MW wrote the manuscript and confirmed the authenticity of the raw data. All authors read and approved the final manuscript.

\section{Ethics approval and consent to participate}

The Ethics Committee of Hebei University of Chinese Medicine (Shijiazhuang, China) approved and supervised the 
present study (approval no. DWLL2018016). The animal treatments in this study were in compliance with the Laboratory Animal Management of National Animal Science and Technology Commission's Regulations (Beijing, China).

\section{Patient consent for publication}

Not applicable.

\section{Competing interests}

The authors declare that they have no competing interests.

\section{References}

1. Annual report on cardiovascular health and diseases in China 2019. Journal of Cardiovascular \& Pulmonary Diseases 39 : 1145-1156, 2020 (in Chinese).

2. Libby P: The molecular mechanisms of the thrombotic complications of atherosclerosis. J Intern Med 263: 517-527, 2010.

3. Zhao X, Zhu J, Wang L, Li Y, Zhao T, Chen X, Sun Y, Dai Y, Wei G, Altamirano A, et al: U. diffracta extract mitigates high-fat diet and VD3-induced atherosclerosis and biochemical changes in the serum liver and aorta of rats. Biomed Pharmacother 120: 109446, 2019.

4. Ding L, Gu H, Lan Z, Lei Q, Wang W, Ruan J, Yu M, Lin J and Cui Q: Downregulation of cyclooxygenase1 stimulates mitochondrial apoptosis through the NF- $\mathrm{KB}$ signaling pathway in colorectal cancer cells. Oncol Rep 41: 559-569, 2019.

5. Akhtar M, Guo S, Guo YF, Zahoor A, Shaukat A, Chen Y, Umar T, Deng PG and Guo M: Upregulated-gene expression of pro-inflammatory cytokines (TNF- $\alpha$, IL- $1 \beta$ and IL-6) via TLRs following NF- $\kappa \mathrm{B}$ and MAPKs in bovine mastitis. Acta Trop 207: 105458, 2020.

6. Rezagholizadeh L, Pourfarjam Y, Nowrouzi A, Nakhjavani M, Meysamie A,Ziamajidi N and Nowrouzi PS: Effect of Cichorium intybus L. on the expression of hepatic NF- $\kappa B$ and IKK $\beta$ and serum TNF- $\alpha$ in $\mathrm{STZ}^{-}$and $\mathrm{STZ}^{+}$niacinamide-induced diabetes in rats. Diabetol Metab Syndr 8: 11, 2016.

7. Moallemian R, Rehman AU, Zhao N, Wang H, Chen H, Lin G, $\mathrm{Ma} X$ and Yu J: Immunoproteasome inhibitor DPLG3 attenuates experimental colitis by restraining NF- $\kappa \mathrm{B}$ activation. Biochem Pharmacol 177: 113964, 2020.

8. Yang CH, Liu XM, Si JJ, Shi HS, Xue YX, Liu JF, Luo YX, Chen $\mathrm{C}$, Li P, Yang JL, et al: Role of IKK/NF- $\kappa \mathrm{B}$ signaling in extinction of conditioned place aversion memory in rats. PLoS One 7: e39696, 2017.

9. Wu C, Yang Y, Ou J, Zhu L, Zhao W and Cui J: LRRC14 attenuates toll-like receptor-mediated NF- $\kappa \mathrm{B}$ signaling through disruption of IKK complex. Exp Cell Res 347: 65-73, 2016.

10. Leibowitz SM and Yan J: NF-kB pathways in the pathogenesis of multiple sclerosis and the therapeutic implications. Front Mol Neurosci 9: 84, 2016.

11. Wu Y, Song F, Li Y, Li J, Cui Y, Hong Y, Han W, Wu W, Lakhani I, $\mathrm{Li} \mathrm{G}$ and Wang Y: Acacetin exerts antioxidant potential against atherosclerosis through Nrf2 pathway in apoE(-/-) mice. J Cell Mol Med 25: 521-534, 2021.

12. Zhang F, Feng J, Zhang J, Kang X and Qian D: Quercetin modulates AMPK/SIRT1/NF-kappaB signaling to inhibit inflammatory/oxidative stress responses in diabetic high fat diet-induced atherosclerosis in the rat carotid artery. Exp Ther Med 20: 280, 2020.

13. Zhu S, Zhang J and Lv Y: Glaucocalyxin A inhibits hydrogen peroxide-induced oxidative stress and inflammatory response in coronary artery smooth muscle cells. Clin Exp Pharmacol Physiol 47: 765-770, 2020.

14. Liu Y, Ni Y, Ruan J, Qu L, Yu H, Han L, Zhang Y and Wang T: Bioactive gentixanthone and gentichromone from the whole plants of Gentianella acuta (Michx.) Hulten. Fitoterapia 113: 164-169, 2016.

15. Wunir, Chunliang, Khasbagan: Ewenki folk medicinal plants and its comparison with mongolian medicine. Chin J Ethnomed Ethnopharm 17: 156-158, 2009 (in Chinese).

16. Ding Z, Liu Y, Ruan J, Yang S, Yu H, Chen M, Zhang Y and Wang T: Bioactive constituents from the whole plants of Gentianella acuta (Michx.) Hulten. Molecules 22: 1309, 2017.
17. Wang Z, Wu Q, Yu Y, Yang C, Jiang H, Wang Q, Yang B and Kuang H: Determination and pharmacokinetic study of four xanthones in rat plasma after oral administration of Gentianella acuta extract by UHPLC-ESI-MS/MS. J Ethnopharmacol 174: 261-269, 2015.

18. Li AY, Wang JJ, Yang SC, Zhao YS, Li JR, Liu Y, Sun JH, An LP, Guan P and Ji ES: Protective role of Gentianella acuta on isoprenaline induced myocardial fibrosis in rats via inhibition of N-kB pathway. Biomed Pharmacother 110: 733-741, 2019.

19. Jindarat S: Xanthones from mangosteen (Garcinia mangostana): Multi-targeting pharmacological properties. J Med Assoc Thai 97 (Suppl 2): S196-S201, 2014.

20. Tantapakul C, Maneerat W, Sripisut T, Ritthiwigrom T, Andersen RJ, Cheng P, Cheenpracha S, Raksat A and Laphookhieo S: New benzophenones and xanthones from Cratoxylum sumatranum ssp. neriifolium and their antibacterial and antioxidant activities. J Agric Food Chem 64: 8755-8762, 2016.

21. Wang Z, Wu G, Yu Y, Liu H, Yang B, Kuang H and Wang Q: Xanthones isolated from Gentianella acuta and their protective effects against H2O2-induced myocardial cell injury. Nat Prod Res 32: 2171-2177, 2018.

22. Yang HX, Xu GR, Zhang C, Sun JH, Zhang Y, Song JN, Li YF, Liu Y and Li AY: The aqueous extract of Gentianella acuta improves isoproterenol-induced myocardial fibrosis via inhibition of the TGF- $\beta 1 /$ Smads signaling pathway. Int J Mol Med 45: 223-233, 2020.

23. Ren K, Su H, Lv LJ, Yi LT, Gong X, Dang LS, Zhang RF and Li MH: Effects of four compounds from Gentianella acuta (Michx.) Hulten on hydrogen peroxide-induced injury in $\mathrm{H} 9 \mathrm{c} 2$ Cells. Biomed Res Int 20: 2692970, 2019.

24. Koo YE, Song J and Bae S: Use of plant and herb derived medicine for therapeutic usage in cardiology. Medicines (Basel) 22: 38, 2018.

25. Guedes L, Reis P, Machuqueiro M, Ressaissi A, Pacheco R and Serralheiro ML: Bioactivities of centaurium erythraea (Gentianaceae) decoctions: Antioxidant activity, enzyme inhibition and docking studies. Molecules 24: 3795, 2019.

26. Wang Z, Wu G, Liu H, Xing N, Sun Y, Zhai Y, Yang B, Kong AT, Kuang $\mathrm{H}$ and Wang Q: Cardioprotective effect of the xanthones from Gentianella acuta against myocardial ischemia/reperfusion injury in isolated rat heart. Biomed Pharmacother 93: 626-635, 2017.

27. Zhang Y and Zhang Y: Pterostilbene, a novel natural plant conduct, inhibits high-fat-induced atherosclerosis inflammation via NF- $\mathrm{kB}$ signaling pathway in toll-like receptor 5 (TLR5) deficient mice. Biomed Pharmacother 81: 345-355, 2016.

28. Kumar SU, Kumar DT, Bithia R, Sankar S, Magesh R, Sidenna M, Doss CG and Zayed H: Analysis of differentially expressed genes and molecular pathways in familial hypercholesterolemia involved in atherosclerosis: A systematic and bioinformatics approach. Front Genet 11: 734, 2020.

29. Tan CX, Chong GH, Hamzah H and Ghazali HM: Effect of virgin avocado oil on diet-induced hypercholesterolemia in rats via $^{1}$ H NMR-based metabolomics approach. Phytother Res 32: 2264-2274, 2018

30. Dettlaff-Pokora A, Sucajtys-Szulc E and Sledzinski T: Up-regulation of PCSK9 gene expression and diminished level of LDL-receptor in rat liver as a potential cause of post-lipectomy hypercholesterolemia. Mol Cell Biochem 455: 207-217, 2019.

31. Adedayo MR, Akintunde JK, Sani A and Boligon AA: Effect of dietary supplement from mono-culture fermentation of Moringa oleifera seeds by Rhizopus stolonifer on hematology and markers linked to hypercholesterolemia in rat model. Food Sci Nutr 6: 1826-1838, 2018.

32. Wang X, Hasegawa J, Kitamura Y, Wang Z, Matsuda A, Shinoda W, Miura N and Kimura K: Effects of hesperidin on the progression of hypercholesterolemia and fatty liver induced by high-cholesterol diet in rats. J Pharmacol Sci 117: 129-138, 2011.

33. Xu Y, Gao J, Gong Y, Chen M, Chen J, Zhao W and Tan S: Hsa-miR-140-5p down-regulates LDL receptor and attenuates LDL-C uptake in human hepatocytes. Atherosclerosis 297: 111-119, 2020.

34. Klein-Szanto AJP and Bassi DE: Keep recycling going: New approaches to reduce LDL-C. Biochem Pharmacol 164: 336-341, 2019.

35. Leko MB, Perkovic MN, Klepac N, Strac DS, Borovecki F, Pivac N, Hof PR and Simic G: IL-1 $\beta$, IL-6, IL-10, and TNF- $\alpha$ single nucleotide polymorphisms in human influence the susceptibility to Alzheimer's disease pathology. J Alzheimers Dis 75: 1029-1047, 2020. 
36. Qin J, Zhao N, Wang S, Liu S, Liu Y, Cui X, Wang S, Xiang Y, Fan C, Li Y, et al: Roles of endogenous IL-10 and IL-10-competent and $\mathrm{CD}^{+} \mathrm{B}$ cells in autoimmune thyroiditis in NOD.H-2h4 mice. Endocrinology 161: 4, 2020.

37. Saliu JA, Oyeleye SI, Olasehinde TA and Oboh G: Modulatory effects of stonebreaker (Phyllanthus amarus) and bitter gourd (Momordica charantia) on enzymes linked with cardiac function in heart tissue of doxorubicin-stressed rats. Drug Chem Toxicol 11: 1-9, 2019.

38. Xian H, Feng W and Zhang J: Schizandrin A enhances the efficacy of gefitinib by suppressing IKK $\beta / N F-\kappa B$ signaling in non-small cell lung cancer. Eur J Pharmacol 855: 10-19, 2019.

39. Li T, Chen RR, Gong HP, Wang BF, Wu XX, Chen YQ and Huang ZM: FGL2 regulates IKK/NF- $\kappa \mathrm{B}$ signaling in intestinal epithelial cells and lamina propria dendritic cells to attenuate dextran sulfate sodium-induced colitis. Mol Immunol 117: 84-93, 2020 .
40. Yan C, Li B, Liu X, Deng C, Cai R, Shen Y and Tang H: Involvement of multiple transcription factors in regulation of IL- $\beta$-induced MCP-1 expression in alveolar type II epithelial cells. Mol Immunol 111: 95-105, 2019.

41. Shin JS, Im HT and Lee KT: Saikosaponin B2 suppresses inflammatory responses through $\mathrm{IKK} / \mathrm{I}-\kappa \mathrm{B} \alpha / \mathrm{NF}-\kappa \mathrm{B}$ signaling inactivation in lps-induced RAW 264.7 macrophages. Inflammation 42: 342-353, 2019.

This work is licensed under a Creative Commons Attribution 4.0 International (CC BY 4.0) License. 